\title{
25. MAGNETIC FABRIC STUDIES OF SAMPLES FROM HOLE 808C, NANKAI TROUGH ${ }^{1}$
}

\author{
W.H. Owens ${ }^{2}$
}

\begin{abstract}
Measurements of magnetic susceptibility anisotropy, orientated using stable remanences, are presented for Hole $808 \mathrm{C}$, over the depth range 300 to 1050 meters below seafloor. Within the accretionary prism, magnetic fabric directions are remarkably consistent, the maximum susceptibility axes lying horizontal and at right angles to the direction of underthrusting, with minimum susceptibility axes generally close to vertical. Steeper inclinations of the minimum susceptibility axes are observed in the fold below the frontal thrust and in a disturbed zone just above the décollement. Anisotropy parameters are scattered, possibly reflecting local inhomogeneity of deformation, but the broad pattern is consistent with the model for magnetic fabric modification put forward by Graham (1966). Below the décollement the magnetic fabric is strongly oblate, with no preferred azimuthal orientation. There is evidence of deformation of remanence in the zone immediately below the frontal thrust.
\end{abstract}

\section{INTRODUCTION}

The tectonic environment of an accretionary prism provides an excellent opportunity to study the effects of deformation on both magnetic fabric and remanence. Hole $808 \mathrm{C}$ is perhaps unique in two respects: in the degree to which complementary information (e.g., on structural geology and physical properties) is available and in the control on orientation that was provided by remanence measurements. The theme of the present paper is, therefore, the modification of magnetic fabric and remanence by deformation, as evidenced by Hole $808 \mathrm{C}$. The paper focuses on the depth interval from 300 to $1050 \mathrm{~m}$ below seafloor (mbsf), which extends from just above the frontal thrust to below the décollement (see review paper, this volume).

Related studies have been carried out by Taira and Niitsuma (1985), in the Nankai Trough, and by Hounslow (1990), in the Barbados accretionary prism. The former concentrated on details of sedimentation of the turbidites that characterize the trench wedge. Hounslow employed an approach similar to that adopted here, but in a tectonic regime that proved to be of considerably greater complexity. For those unfamiliar with magnetic fabric studies, a useful starting reference is Collinson (1983).

\section{SAMPLING AND MEASUREMENT}

In view of the problems inherent in obtaining undisturbed samples when using sampling cubes, measurements were restricted to drilled, cylindrical samples. "Minicores" of nominally $2.54 \mathrm{~cm}$ ( 1 in.) diameter were taken from the working half of the core. To preserve parallelism of the minicore axis to the core reference direction, previously marked portions of the working half were removed, inverted onto a flat wooden surface, and drilled on a bench press from outside in. Samples were subsequently sawed to length (nominally $2.2 \mathrm{~cm}$ ) onshore.

Problems were experienced due to the friability of samples (exacerbated by samples drying out in the fan-driven cooling of the alternating field demagnetizer). These problems were particularly acute for samples taken from just above the décollement; the samples required some delicate reconstruction.

'Hill, I. A., Taira, A., Firth, J.V., 1993. Proc. ODP, Sci. Results, 131: College Station, TX (Ocean Drilling Program).

${ }^{2}$ School of Earth Sciences, University of Birmingham, Birmingham B15 2 TT, United Kingdom.
Remanence measurements were made on a Molspin fluxgate spinner magnetometer. For alternating field demagnetization a Highmoor demagnetizer was used. This has a two-axis tumbler, which was modified to alternate the sense of tumbling to minimize the introduction of rotational remanences. Some of the weaker specimens were measured, at the University of Southampton, on a cryogenic magnetometer with an inbuilt static-sample demagnetizer.

Anisotropy of initial (low field) magnetic susceptibility was measured on a Molspin Minisep instrument, in which anisotropy is measured by detecting the component of magnetization induced at right angles to the direction of an applied, weak (nominally $0.7 \mathrm{mT}$ ), alternating magnetic field.

\section{REMANENCE}

On Leg 131 remanence was measured for the purposes of magnetostratigraphy and to provide a means of sample orientation.

The magnetostratigraphic applications have been reported previously (Shipboard Scientific Party, 1991) and are not discussed further, except to make two points that arise from that contribution:

1. The primary source of data for magnetostratigraphic purposes is the shipboard, $2 \mathrm{G}$ continuous-core cryogenic magnetometer. Discussion in Shipboard Scientific Party (1991) touched on the interpretation of the continuous-core records produced by the data-analysis program currently in use. Errors, in the form of oversteepened inclinations, can arise when, for example, uniformly magnetized core is broken into segments, which are short compared with the averaging distance of the sensors, and which are rotated relative to each other (Shipboard Scientific Party, 1991, pp. 45-46). An obvious extension of this argument, although not stated explicitly previously, is that, in such cases, the lower limit of the scattered values, rather than the average, will provide the best estimate of the remanence inclination. This is well illustrated by the figure accompanying the discussion (Shipboard Scientific Party, 1991, Fig. 14).

2. Measurements on discrete, minicore samples are made as an adjunct to the continuous-core cryogenic measurements made on board, primarily because they allow alternating-field demagnetizations to be taken to higher fields than is permitted on the archive half of the core. The shipboard measurements made using a static-sample demagnetizer indicated that at high demagnetization fields spurious remanences were clearly being introduced. Subsequent shore-based measurements using a rotating-sample demagnetizer showed that some samples were prone to acquire a significant rotational rema- 
nence. It may therefore be that the original shipboard measurements indicate the acquisition of a gyroremanent magnetization (Stephenson, pers. comm., 1991; Stephenson, 1980).

In this paper we are concerned primarily with the use of remanence for sample orientation. The criteria that must be satisfied were discussed in Shipboard Scientific Party (1991), pp. 126-128. The essential requirements are a stable magnetization acquired in a known field and that any tectonic corrections required are known. The last is not a serious concern for most of the core from Hole 808C, as evidence (see below) suggests that zones of significant bedding dip are localized. The requirement of a known field limits application to periods of stable normal or reversed polarity, and the avoidance of cases where the inclination, or the sample position relative to the reversal sequence, suggests a polarity transition. With regard to stability, evidence comes, in general, from alternating field demagnetization studies. (The hole has, additionally, provided a convincing example of the fold test-a classic, geological stability test (Graham, 1949). This was described previously (Shipboard Scientific Party, 1991, pp. 124, 126; Figs. 76, 77) and is referred to again below).

Figure 1 summarizes the inclinations of discrete-sample remanences judged as stable, on the basis of alternating-field demagnetization, and places them in the context of the polarity reversal stratigraphy identified for Hole 808C. (Recovery was too incomplete for this to be extended beyond $1100 \mathrm{mbsf}$.) There is a general clustering about $\pm 40^{\circ}$ inclination (shallower than the inclination of $52^{\circ}$ for an axial dipole field and present latitude); remanences with inclinations that depart significantly from this cannot be used for orientation purposes.

One means available for testing, independently, the reliability of remanence-based orientation is to examine internal consistency between remanence directions from samples taken from an intact piece of core. Shipboard sampling was not directed toward this end, so evidence is limited. In one case three samples agreed in declination within $3^{\circ}$, in another within $28^{\circ}$.

\section{ANISOTROPY OF MAGNETIC SUSCEPTIBILITY}

\section{Anisotropy Parameters}

Low-field magnetic susceptibility is a second-rank, symmetric tensor and has six independent elements. It is standard practice to express these in terms of three principal susceptibilities, or some combination of them (three independent elements) and the orientation of an orthogonal set of principal axes (three independent elements). The choice of magnitude parameters is somewhat arbitrary: what matters is that, in principle, the tensor can be reconstructed from the information provided. In the present work the parameters chosen are:

$$
\begin{gathered}
\bar{K}=\left(k_{\max }+k_{\text {int }}+k_{\min }\right) / 3 \\
H=\left[\left(k_{\max }-k_{\min }\right) / \bar{K}\right] \times 100 \\
\mu=\tan ^{-1}\left[\left(k_{\max }-k_{\text {int }}\right) /\left(k_{\text {int }}-k_{\min }\right)\right] .
\end{gathered}
$$

These parameters are related to those used previously (for example by Owens and Bamford, 1976). The first, $\bar{K}$, is the mean susceptibility and is related to the amount of source material in a sample: if the source material is magnetite the mean susceptibility (in SI units) is approximately three times the volume fraction of magnetite present (Mooney and Bleifuss, 1953). The second, $H$, the "percentage (or total) anisotropy," is a measure of the "strength" of the anisotropy, and the third, $\mu$, is a measure of the "shape" of the anisotropy. If $\left(k_{\max }-k_{\text {int }}\right)$ and $\left(k_{\text {int }}-k_{\min }\right)$ are taken as relative measures of "lineation" and "foliation," $\mu$ expresses the angle of slope of a line drawn from the origin to a point on a lineation vs. foliation plot. Thus, $\mu=0^{\circ}$ indicates an oblate fabric and $\mu=90^{\circ}$ a prolate fabric.

\section{Inclination}

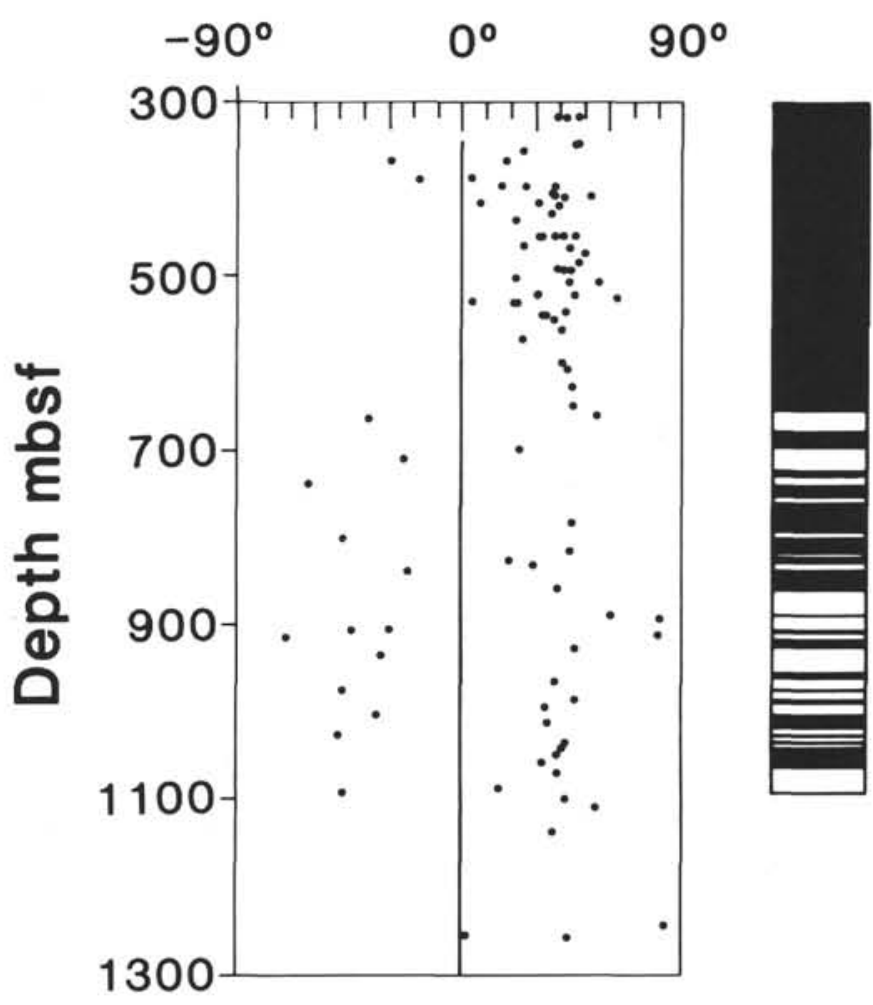

Figure 1. Remanence inclination vs. depth for discrete samples from Hole $808 \mathrm{C}$, and comparison with previously inferred polarity variations.

\section{RESULTS \\ General}

The principal axis directions from Hole $808 \mathrm{C}$ show an astounding degree of directional consistency. Figure 2, for example, plots results for all samples between the disturbed zones of the frontal thrust and the décollement (400-935 mbsf). The high degree of internal consistency shown (here, and also in the structural observations: compare, for example, Figure 61 of Shipboard Scientific Party, 1991) provides strong justification, in general, for the remanence-based procedure used to orientate samples. It also requires, of course, a high degree of directional stability in the process that produced the magnetic fabric. (In Fig. 2 and similar figures, the plot of anisotropy parameters may contain data for more samples than the stereogram: samples, although unorientated, may nevertheless provide information on the anisotropy parameters.)

Two other characteristics of the data set stand out. The first is the marked contrast in fabric styles observed above and below the décollement. Figure 2 may be contrasted with Figure 3, which indicates that below the décollement the magnetic fabric is very close to oblate, flattened in the bedding, with no clear grouping of principal axes within the magnetic foliation plane (though it should be remembered that, as the fabric shape approaches oblate, the orientations, within the magnetic foliation plane, of the maximum and intermediate susceptibility axes will become progressively less well defined).

The other notable characteristic is that, even above the décollement, the magnetic fabric is generally flat-lying. Apart from the disturbed regions associated with the décollement and with the frontal thrust ( $360-400 \mathrm{mbsf}$ ), which is discussed in more detail below, there is only one section (Section 131-808C-25R-1) in which the minimum 


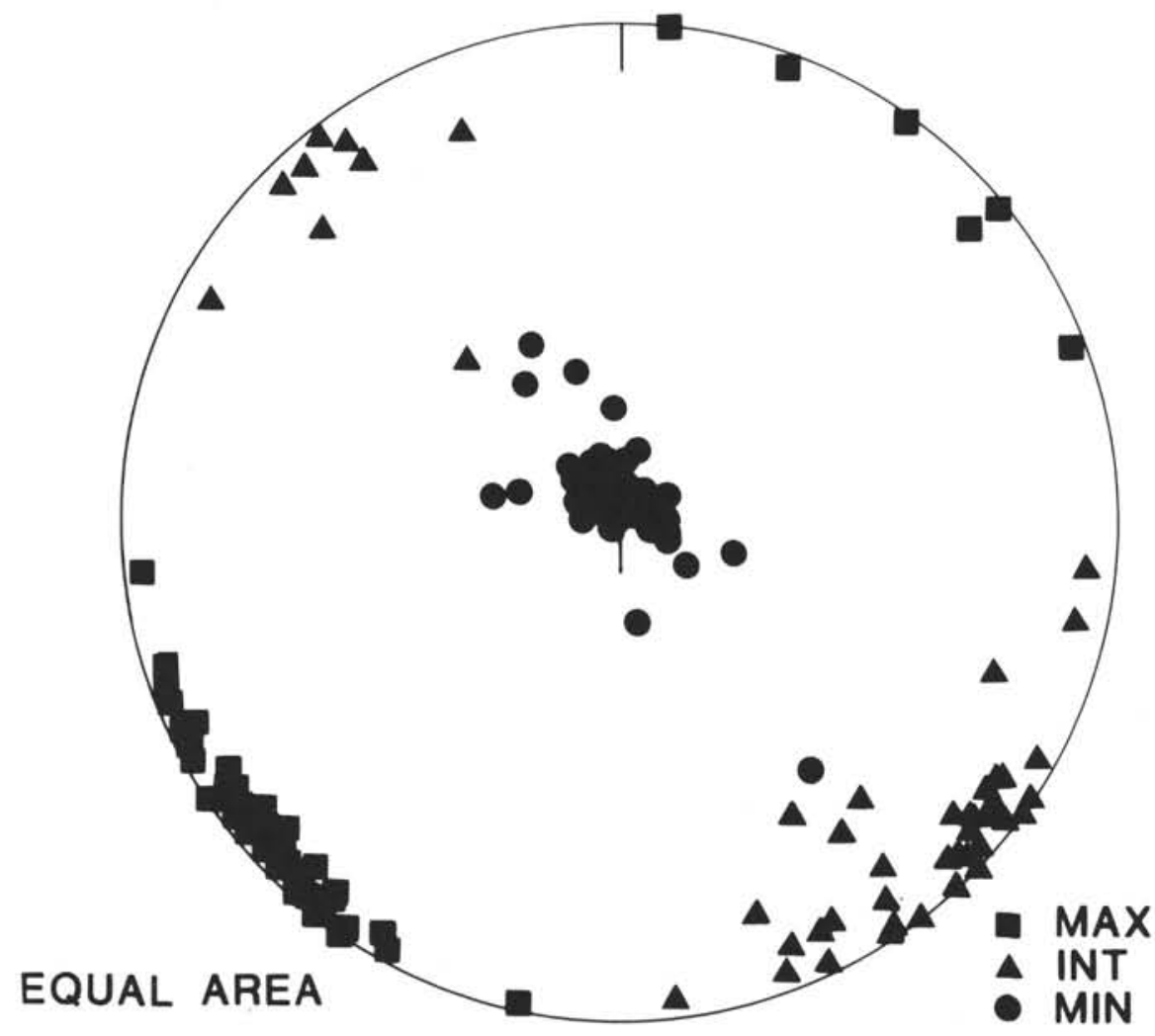

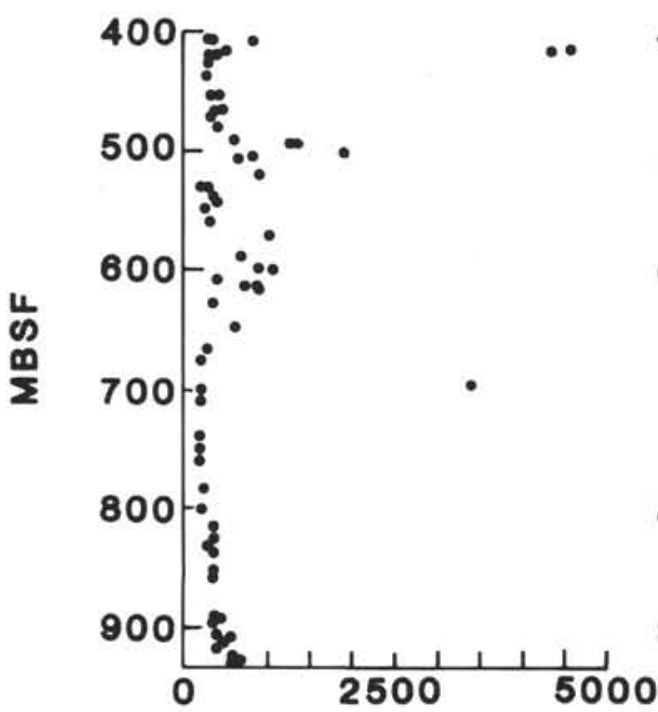

SUSCEPTIBILITY

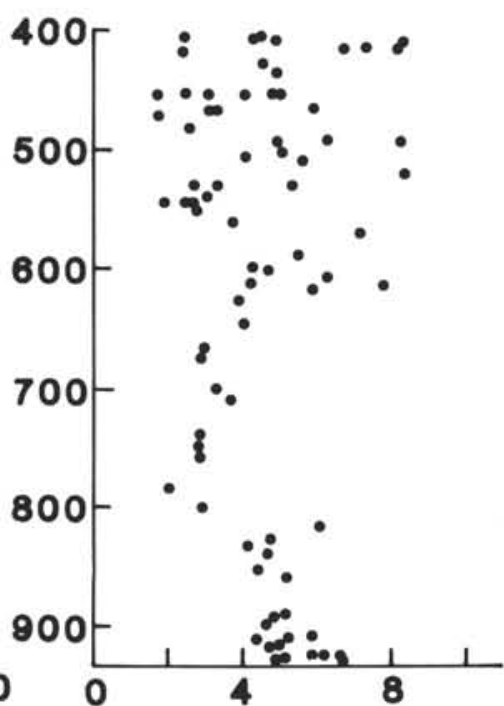

H

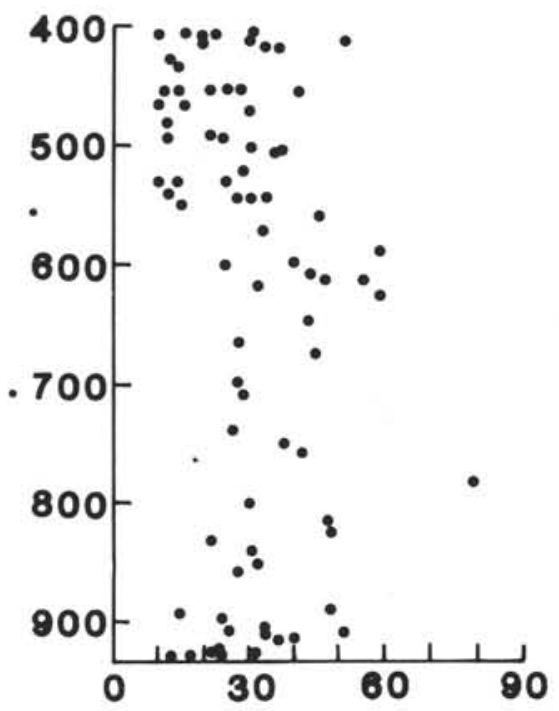

$\mu$

Figure 2. Principal susceptibility directions and anisotropy parameters for all samples in the depth range 400-935 mbsf (between the disturbed zones of the frontal thrust and the décollement). Equal-area, lower hemisphere plot.

susceptibility axis is more than $20^{\circ}$ from the vertical. (In one other sample, Sample 131-808C-51R-2, 114-116 cm, the minimum susceptibility axis is shallow, but the magnetic fabric of that sample is extremely (and atypically) prolate $\left(\mu=79^{\circ}\right)$, and the minimum axis orientation is consequently ill-defined. These observations are brought out clearly in Figures 4 and 5. They stand in marked contrast to the complexities recorded for Leg 110 (Hounslow, 1990).

\section{The Frontal Thrust}

Cores 131-808C-8R through - $11 \mathrm{R}$ contain material from the footwall side of the frontal thrust, in which bedding has been folded and, immediately beneath the thrust, overturned. Parallel changes are observed in the magnetic fabric, the dip of the magnetic foliation plane following the bedding dip around the fold (see Figure 6). 


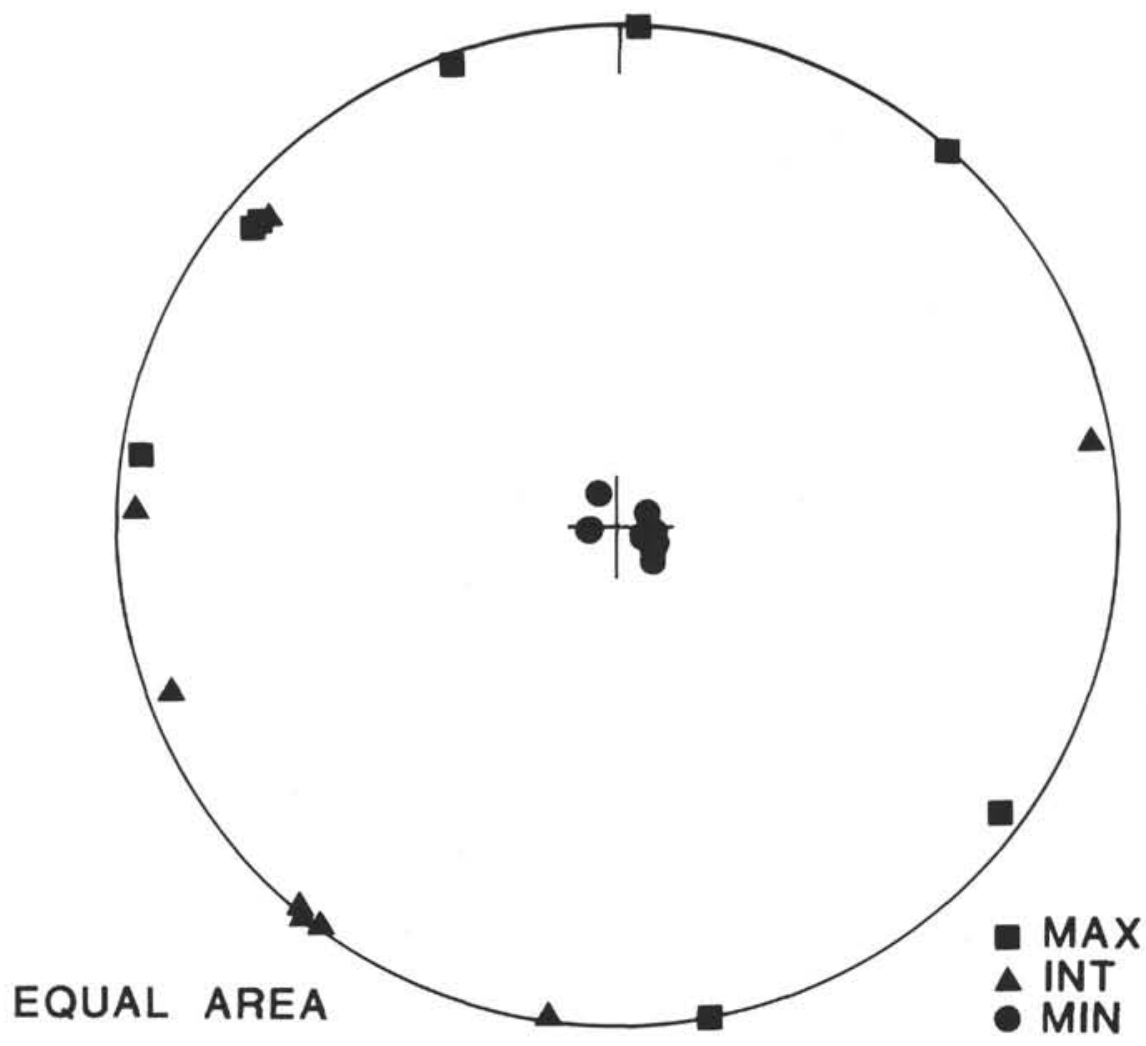

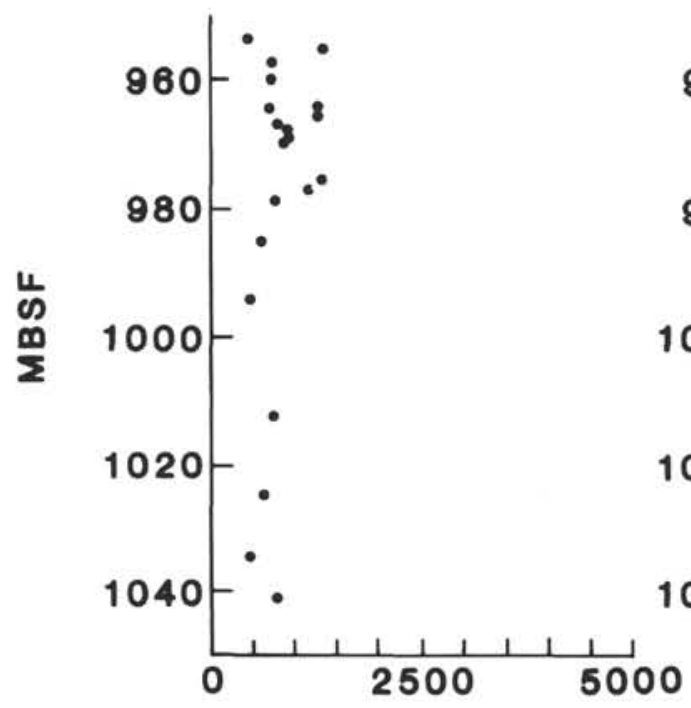

SUSCEPTIBILITY

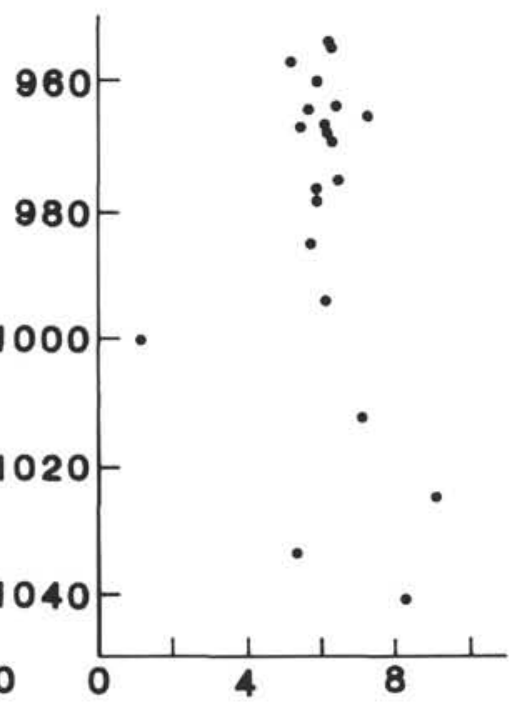

H

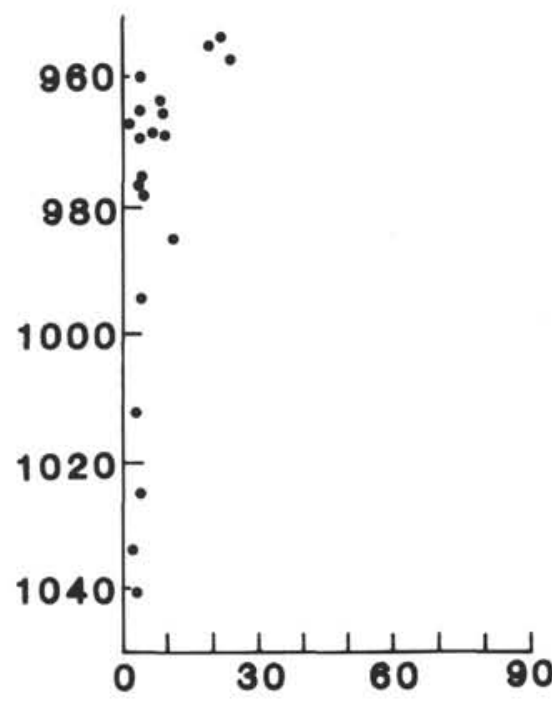

$\mu$

Figure 3. Principal susceptibility directions and anisotropy parameters for all samples in the depth range 950-1050 mbsf (below the décollement). Equal-area, lower hemisphere plot.

Magnetic fabric measurements for the frontal thrust are shown in Figure 7. Maximum susceptibility axes are consistently close to horizontal and palaeomagnetically determined declinations group on a NE-SW trend for all cores except Core 131-808C-8R. It was argued in Shipboard Scientific Party (1991) that, in the particular circum $r$ stances of fold axis declination and field inclination encountered at Hole $808 \mathrm{C}$, tectonic rotation of the remanence (assuming that it rotated with the bedding) would not introduce large errors in orientation, so the grouping of maximum susceptibility axes can be taken as part of the general pattern (compare Fig. 2). In considering the data from Core 131-808C-8R, we can use this general consistency of maximum susceptibility azimuths to invert the argument used for core orientation and hence to infer the behavior of the remanence as it becomes involved in the folding. The original argument (in Shipboard 


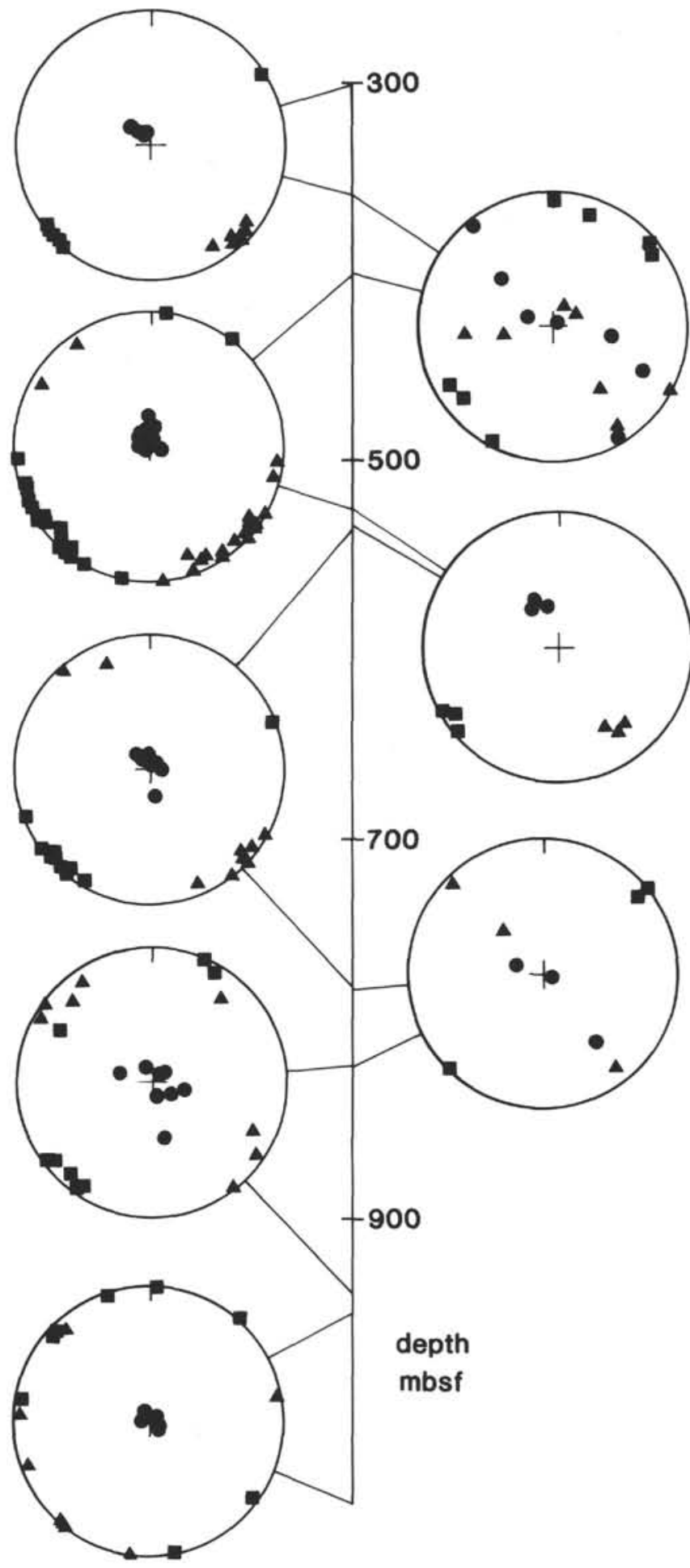

Figure 4. Synoptic plot of stereograms showing directions of principal susceptibility axes, 300-1050 mbsf. (Equal-area, lower hemisphere plots; square-maximum susceptibility, triangle-intermediate susceptibility, circleminimum susceptibility.)

Scientific Party, 1991, pp. 124, 126, 156157) was based, simplistically, on a folding model in which the remanence was rotated rigidly with the bedding during folding. We can extend this model, again simplistically, to consider the deformation as consisting of two components: rigid body rotation and simple shear parallel to the thrust plane, in the direction of transport (see Fig. 8). The remanence is taken to behave as a passive linear element. Rigid body rotation moves the remanence from its undeformed position (assumed parallel to the paleofield direction) around a small circle about the fold axis (compare Shipboard Scientific Party, 1991, Fig. 78). Simple shear moves it off this path along a great-circle path that ultimately, at infinite shear, would lead to the transport direction in the plane of shear (Fig. 8). The exact path followed depends on the partitioning of the deformation between rotation and shear. This model is a gross simplification and clearly cannot be applied quantitatively. Nevertheless, it offers a qualitative explanation for the shallowing of the negative inclinations (below those expected for rigid rotation alone) that are observed in Core 131-808C-8R (see Shipboard Scientific Party, 1991, Fig. 77), and for the relative displacement of the maximum susceptibility axes from those of other cores, which is seen in Figure 7. In so doing it provides a moderately constrained example of the modification of a remanence direction by penetrative deformation.

\section{DISCUSSION}

The distribution of principal susceptibility axes reflects the overall tectonic framework: maximum axes of susceptibility are horizontal and at right angles to the direction of underthrusting; minimum axes in general are perpendicular to bedding.

The geological setting and observed variation in magnetic fabric style suggest that the model first proposed by Graham (1966) gives an appropriate framework for discussion. This considers the modification of an initial, bedding/compaction grain (and hence magnetic) fabric (i.e., a nearly oblate fabric, which may contain a weak magnetic lineation, due, for example, to grain alignment by paleocurrents) by plane strain, with bedding-parallel compression and extension normal to bedding. The early stages of fabric modification are first, that the maximum susceptibility moves rapidly within the bedding plane into the intermediate- (or no-) strain direction and that, subsequently, the fabric shape becomes more prolate until the intermediate and minimum susceptibility axes interchange their directions. In Hole $808 \mathrm{C}$ we see a variation in fabric style that approaches, but does not reach, the prolate stage. Calculations by Owens (1974) indicated that, as the fabric shape moved from oblate toward prolate, the strength of the anisotropy should decrease. To investigate this suggestion, Figure 9 plots the "shape" parameter, $\mu$, against the "strength" parameter, $H$, for all samples. In Figure 10 subsets of the data are plotted in similar fashion.

The pattern in the synoptic plot demonstrates an upper bound to the data which is broadly in keeping with the suggestion, but the subsets indicate a range of variation. The upper bound is roughly defined by samples from the frontal thrust. Within this zone (360-400 mbsf) there is a general tendency for samples from the fold hinge (Core 131-808C-10R) to be more prolate, with correspondingly weaker anisotropies, as anticipated, though the data are scattered. The fact that the samples in this zone plot toward the upper bound may indicate a general increase of strain intensity within the zone.

The explanation for the general scatter of points below the upper bound, for other samples taken from above the décollement, is at present unclear and further work will be necessary. A weaker starting fabric, due possibly to differences in grain size or degree of bioturbation or to mineralogical variations in the magnetic carriers, could generate parallel paths of $\mu$ vs. $H$ variation. Local strain inhomogeneities could lead to departures from these paths.

The overall pattern above the décollement suggests that, whatever other factors apply, local strain inhomogeneities are likely to be significant.

Below the décollement the contrast in fabric style is again apparent: relatively strong, oblate magnetic fabrics are obtained, indicative of a uniaxial flattening.

There are no obvious correlations between the magnetic anisotropy parameters and the lithostratigraphic variations, which range from turbidite-dominated to hemipelagic. Susceptibility variations related 

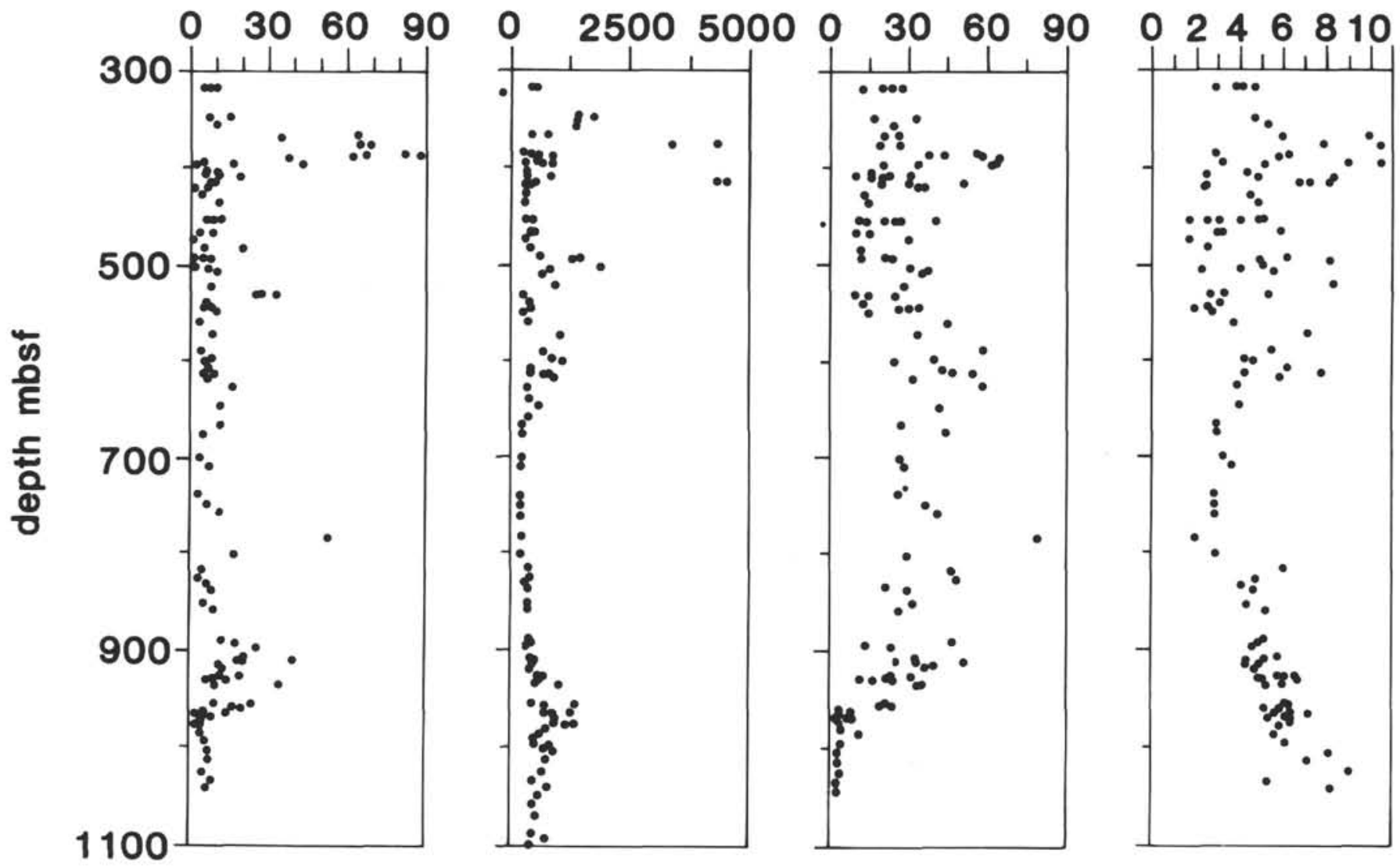

Figure 5. Summary plot of parameters, 300-1050 mbsf: dip of magnetic foliation (maximum/intermediate principal axis) plane, susceptibility $(\bar{K}), \mu$, and $H$.

to sediment type are obvious (Fig. 5); these may influence the magnetic fabric in more subtle ways, by varying the relative importance of magnetite and other minerals in determining the magnetic anisotropy.

\section{CONCLUSIONS}

There is a clear contrast between the magnetic fabric styles observed below and above the décollement (compare Figs. 2 and 3). Above the décollement there is a remarkable consistency of magnetic fabric orientation, both internally and within the regional geological framework. This provides ample demonstration that sample orientation based on remanence directions is, in this instance, reliable. Above the décollement, anisotropy parameters are, even on a local scale, scattered: this suggests some degree of strain inhomogeneity.

Such is the consistency of fabric directions above the décollement that it might be suggested that if, in a similar tectonic regime, remanence control were lacking, anisotropy of susceptibility measurements might be used to provide an internal reference frame (albeit modulo $180^{\circ}$ ).

\section{ACKNOWLEDGMENTS}

The shipboard contributions of many people, and of the paleomagnetics technician, Daniel Bontempo, in particular, made this work possible. I also thank E. Hailwood for access to facilities in Southampton.

\section{REFERENCES}

Collinson, D.W., 1983. Methods in Rock Magnetism and Palaeomagnetism: London (Chapman and Hall).
Graham, J.W., 1949. The stability and significance of magnetism in sedimentary rocks. J. Geophys. Res., 54:131-167.

, 1966. Significance of magnetic anisotropy in Appalachian sedimentary rocks. In Steinhard, J.S., and Smith, T.J. (Eds.) The Earth Beneath the Continents. Geophys. Monogr., Am. Geophys. Union, 10:627-648.

Hounslow, M.W., 1990. Grain fabric measured using magnetic susceptibility anisotropy in deformed sediments of the Barbados Accretionary Prism: Leg 110. In Moore, J.C., Mascle, A., et al., Proc. ODP, Sci. Results, 110: College Station, TX (Ocean Drilling Program), 257-275.

Mooney, H.M., and Bleifuss, R., 1953. Magnetic susceptibility measurements in Minnesota. Part II: Analysis of field results. Geophysics, 18:383-393.

Owens, W.H., 1974. Mathematical model studies on factors affecting the magnetic anisotropy of deformed rocks. Tectonophysics, 24:115-131.

Owens, W.H., and Bamford, D., 1976. Magnetic, seismic and other anisotropic properties of rock fabrics. Philos. Trans. R. Soc. London A, 283: 55-68.

Shipboard Scientific Party, 1991. Site 808. In Taira, A., Hill, I., Firth, J.V., et al., Proc. ODP, Init. Repts., 131: College Station, TX (Ocean Drilling Program), 71-272.

Stephenson, A., 1980. Gyromagnetism and the remanence acquired by a rotating rock in an alternating field. Nature, 284:48-49.

Taira, A., and Niitsuma, N., 1985. Turbidite sedimentation in the Nankai Trough as interpreted from magnetic fabric, grain size and detrital modal analyses. In Kagami, H., Karig, D.E., Coulbourn, W.T., et al., Init. Repts. DSDP, 87: Washington (U.S. Govt. Printing Office), 611-632.

Date of initial receipt: 11 February 1992

Date of acceptance: 12 June 1992

Ms 131SR-130 


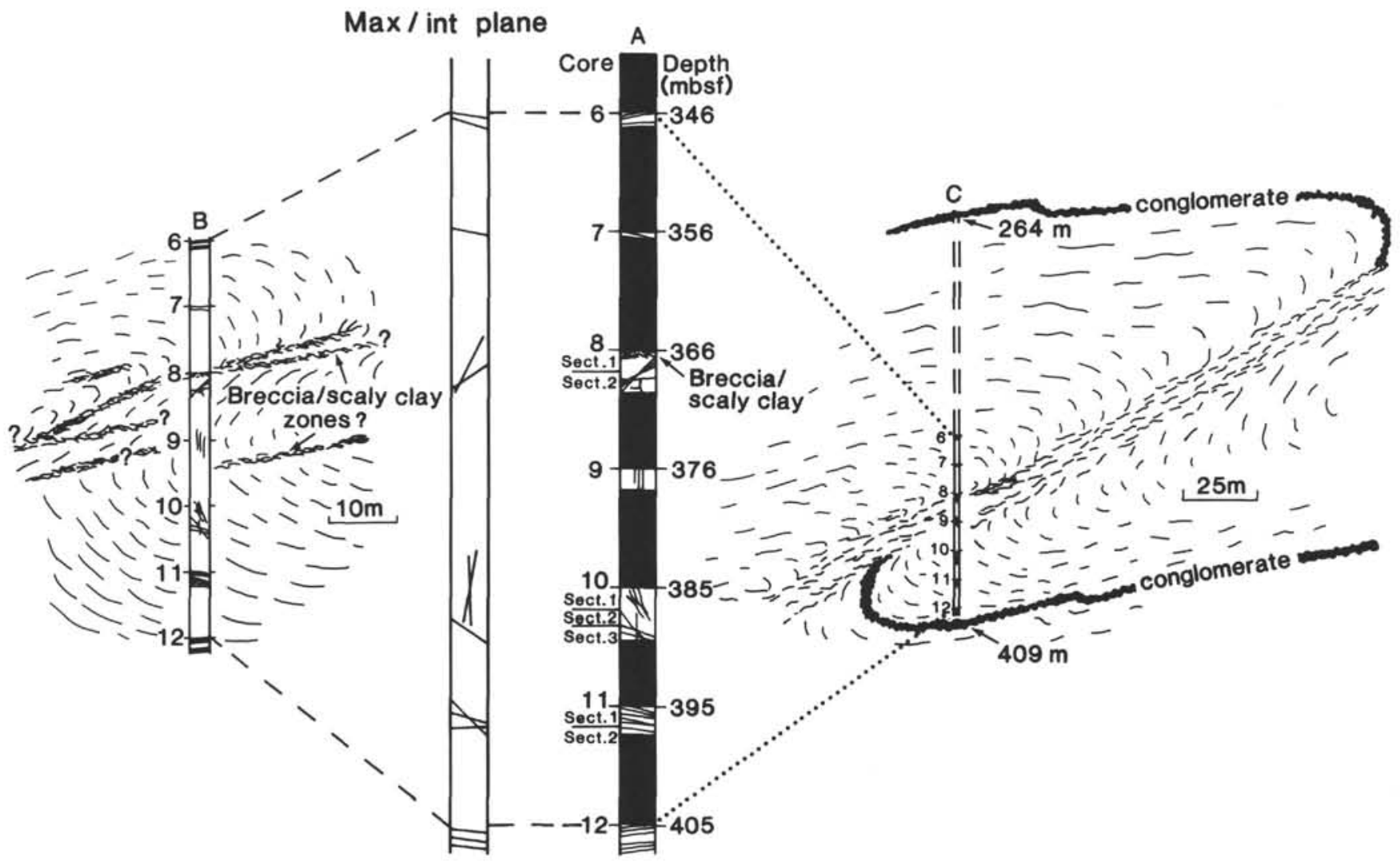

Figure 6. Comparison of the magnetic foliation plane inclination to structural interpretation for the frontal thrust and fold. (After Fig. 63 of Shipboard Scientific Party, 1991.) 


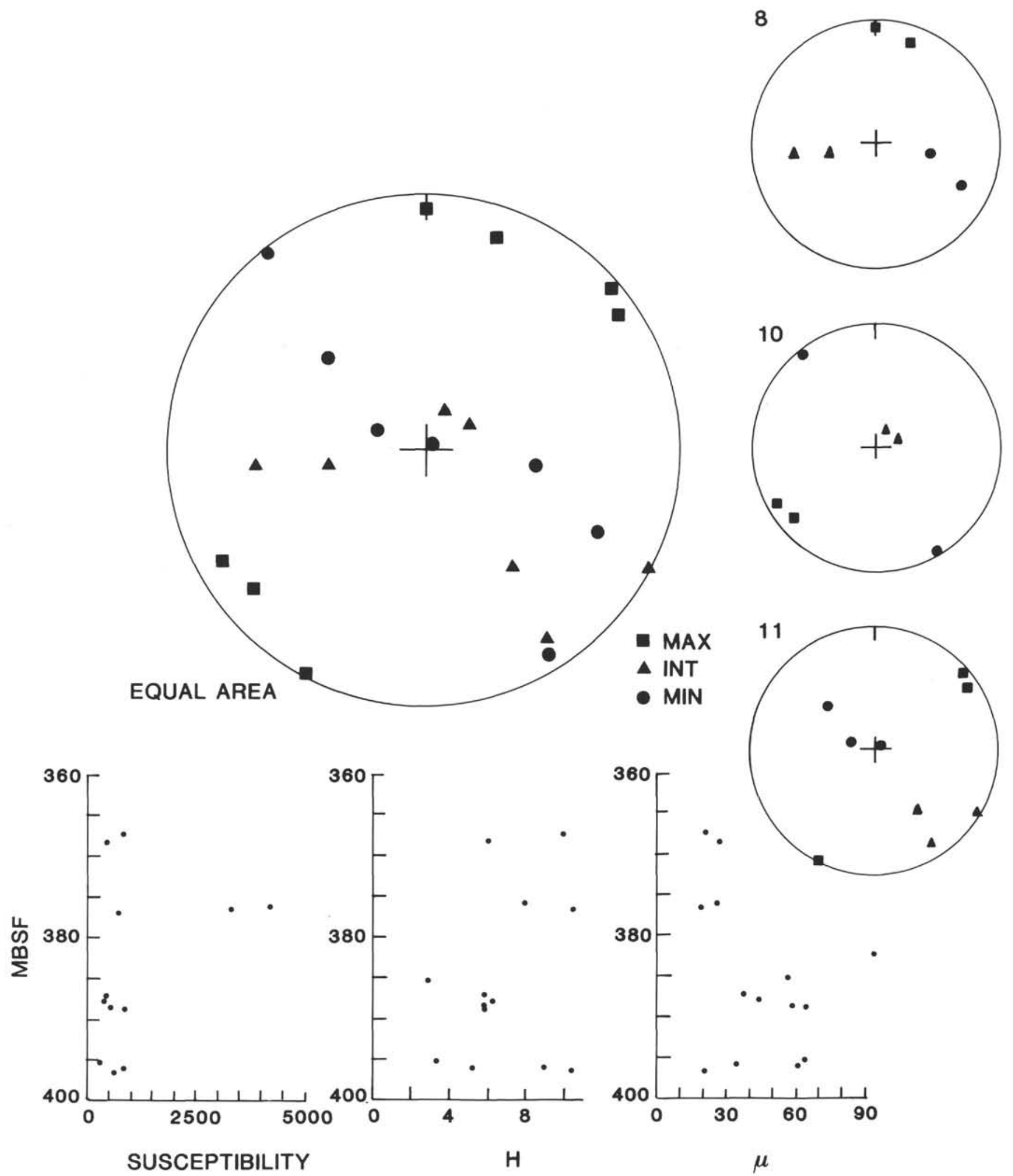

Figure 7. Principal susceptibility directions and anisotropy parameters for all samples in the depth range $360-400$ mbsf (frontal thrust and fold). The inset stereograms record separately the principal axis directions for Cores $131-808 \mathrm{C}-8 \mathrm{R},-10 \mathrm{R}$, and $-11 \mathrm{R}$. 


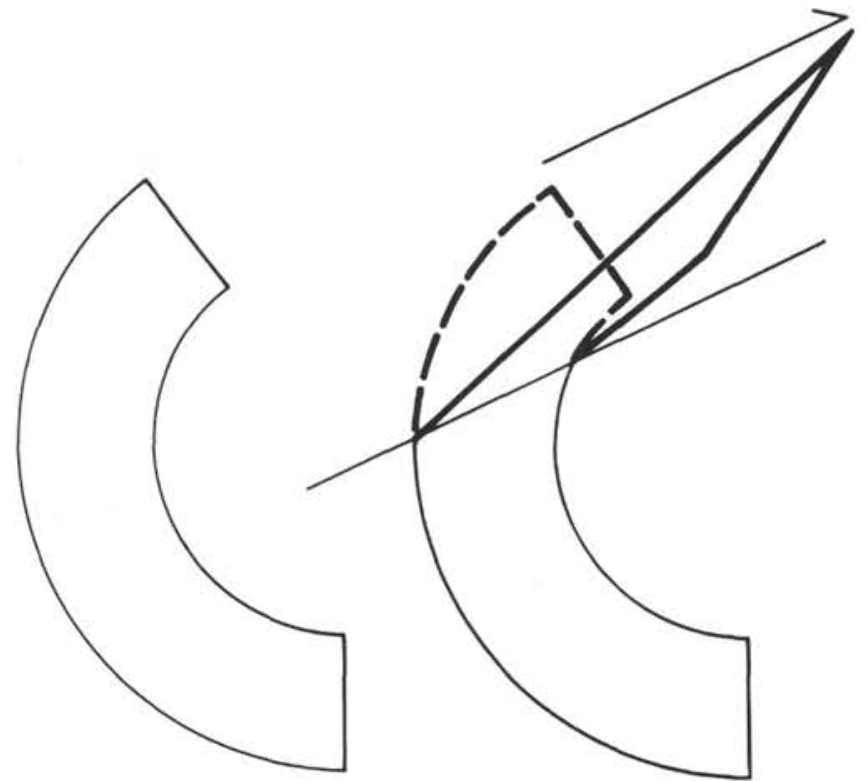

Rotation

Simple Shear

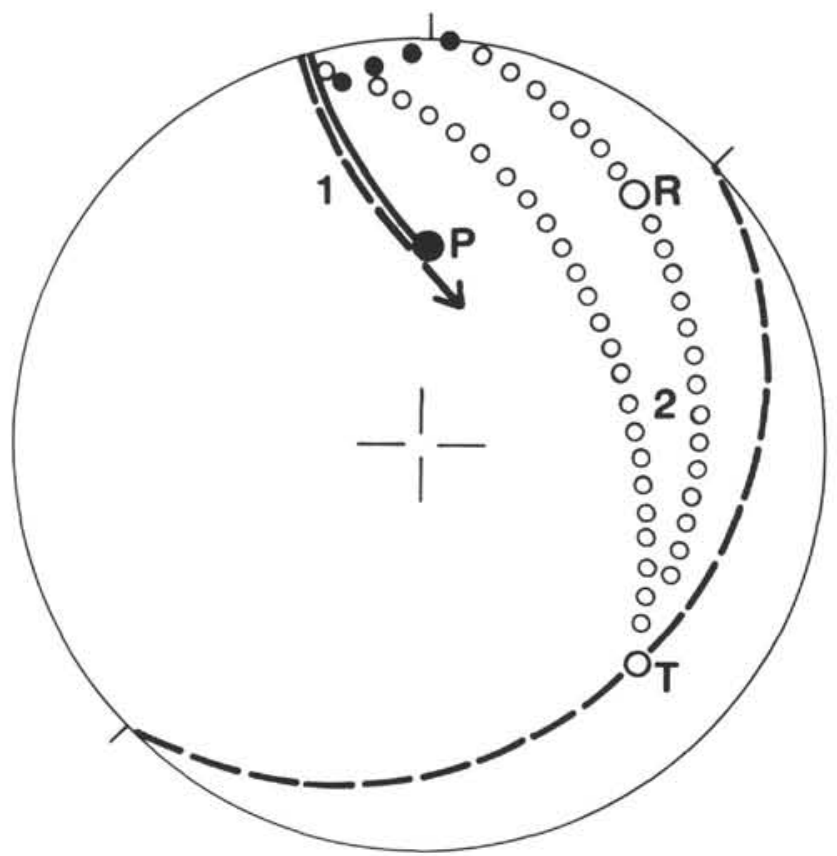

\section{P : Paleofield \\ R : Remanence}

\section{T : Transport direction}

\section{Deformation : 1 : Rotation \\ 2 : Simple Shear}

Figure 8. Folding model and remanence behavior: Folding is approximated by rigid rotation and subsequent simple shear. Remanence, treated as a passive, linear element, follows, respectively, small- and great-circle paths. See text for discussion.

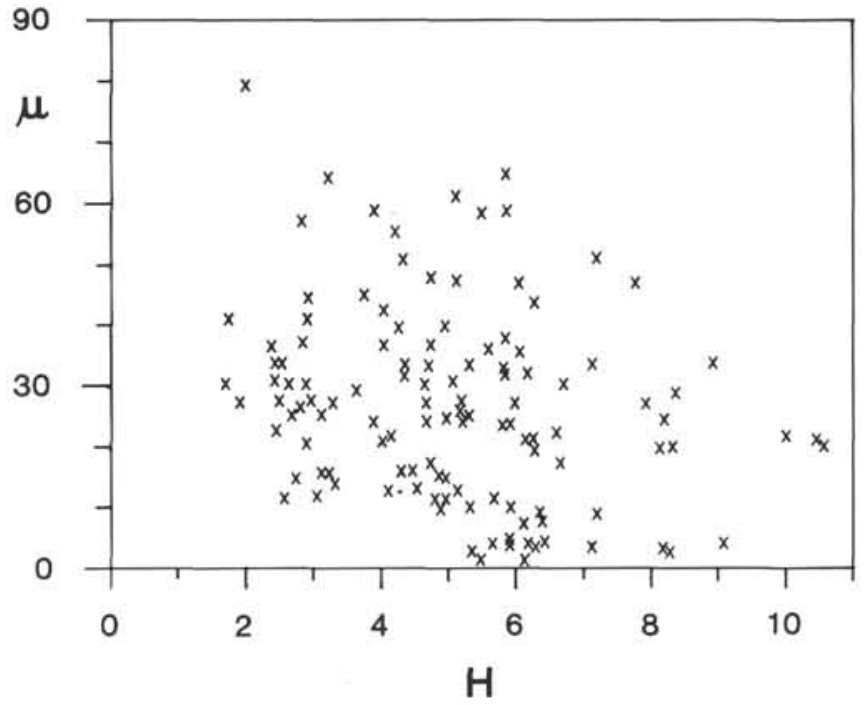

Figure 9. Synoptic plot of $\mu$ vs. $H, 300-1050$ mbsf. 

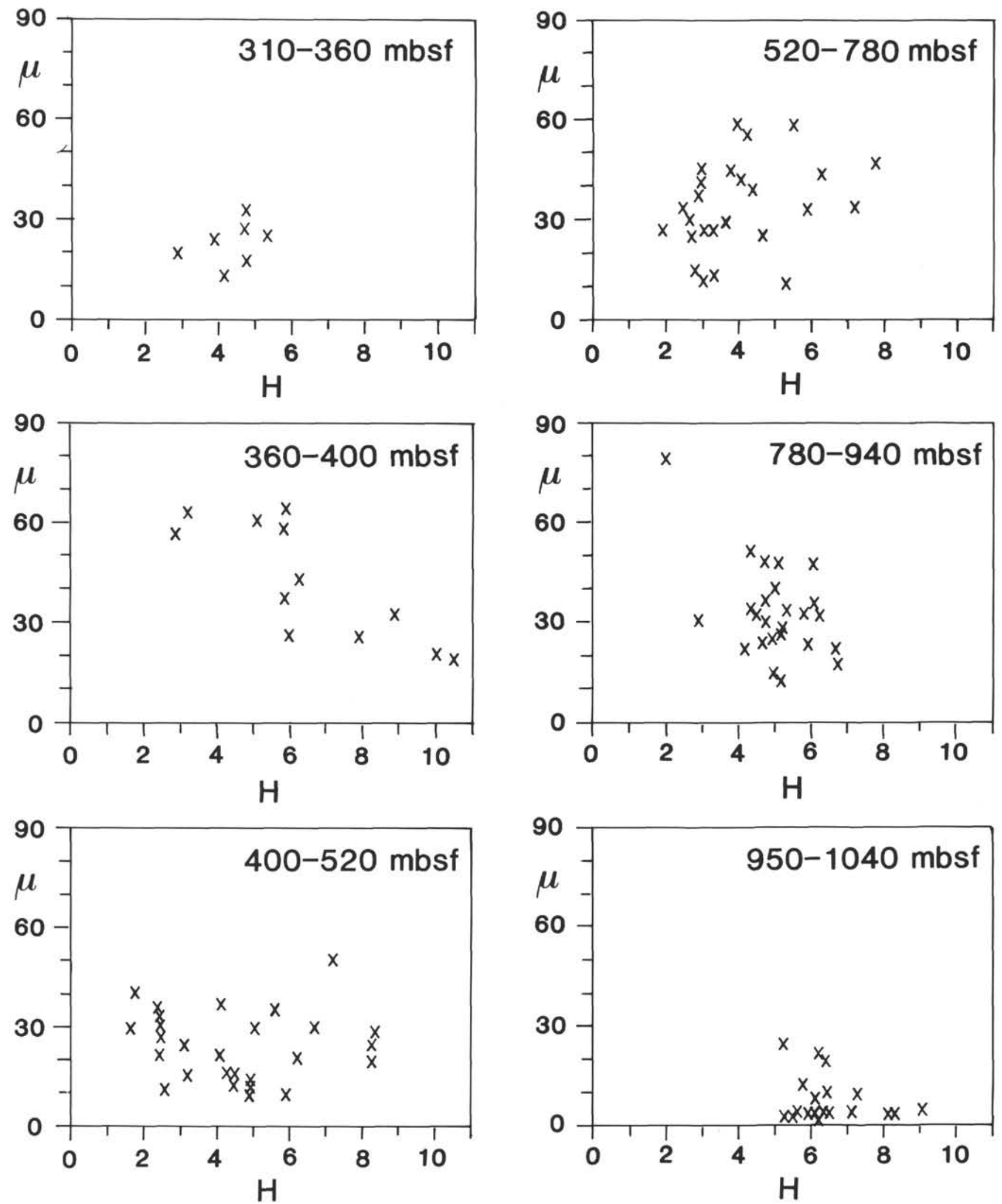

Figure 10 . Plots of $\mu$ vs. $H$, broken down by depth range. 